\title{
Efeitos Contábeis dos Custos de Transação em Operações por encomenda de Equipamentos de Grande Porte
}

Isielli Mayara Barzotto Martins Tierling
Mestrado em Desenvolvimento Regional e Agronegócio pela Universidade Estadual do
Oeste do Paraná - UNIOESTE
Professora da Universidade Estadual do Paraná - UNESPAR
Av. Comendador Norberto Marcondes, 733. Centro. Campo Mourão/PR. CEP: $87302-$

060

E-mail: professora.isi@gmail.com

Juliane Andressa Pavão

Mestrado em Ciências Contábeis pela Universidade Estadual de Maringá - UEM

Professora da Universidade Estadual do Paraná - UNESPAR

Av. Comendador Norberto Marcondes, 733. Centro. Campo Mourão/PR. CEP: 87302-

060

E-mail: julianepavao@hotmail.com

Ivete Julieta Barzotto

Graduação em Ciências Contábeis pela Universidade Estadual do Paraná - UNESPAR Contabilista na empresa Bisi Contabilidade e Assessoria Ltda Rua São Paulo, 1237. Centro. Campo Mourão/PR. CEP: 87.300-390

E-mail: ivete@bisiassessoria.com.br

Amanda Maria da Silva Graduação em Ciências Contábeis pela Universidade Estadual do Paraná - UNESPAR Compradora na empresa Uniprest Ind. e Com. de Máquinas Ltda Av. Aparecido Rorato, 1301. Parque Industrial. Araruna/PR. CEP: 87.260-000 E-mail: amanda_m2008@hotmail.com

\section{RESUMO}

Os custos de transação, também denominados custos de negociação, representam custos econômicos que influenciam o processo de tomada de decisão. Por sua vez, o processo de tomada de decisão é influenciado pelas informações contábeis. Este estudo analisou uma empresa fabricante de máquinas e equipamentos de grande porte, tendo como objetivo identificar quais são os custos de transação presentes nas operações de comercialização de máquinas e equipamentos para indústria de farinha de mandioca, quais elementos determinam a existência desses custos e como eles afetam os resultados contábeis. Utilizou-se das técnicas da pesquisa qualitativa, com coleta de dados documental por meio do modelo de contrato padrão, além de entrevista. Os dados foram analisados à luz da Teoria dos Custos de Transação, cujos resultados foram apresentados de forma descritiva. A análise permitiu concluir que os custos de transação afetam o agente vendedor por meio de possíveis custos de 
Efeitos Contábeis dos Custos de Transação em Operações por encomenda de Equipamentos de Grande Porte

Isielli Mayara Barzotto Martins Tierling, Juliane Andressa Pavão, Ivete Julieta Barzotto, Amanda Maria da

produção adicionais, e também afetam o agente comprador, de modo a elevar o preço de aquisição do equipamento, aumentar os custos de instalação, e provocar perdas no investimento realizado ou imobilizado adquirido. Uma vez que as operações analisadas não se enquadram nas regras contidas na NBC TG 08 , os custos de transação são elementos que afetam a determinação do preço de venda e são evidenciados por meio dos princípios e legislação contábil.

Palavras-chave: Custo de transação. Custos de negociação. Contratos.

\section{Accounting Effects of Transaction Costs in Ordering Operations for Large Equipment}

\section{ABSTRACT}

Transaction costs, also called trading costs, represent economic costs that influence the decision-making process, which is influenced by accounting information. This study aims to identify the transaction costs in the commercialization operations and which costs affect the accounting results of a company that manufactures large machines and equipment. To accomplish this objective it was carried out a qualitative research, by collecting documentary data found in the standard contract model, in addition to the interview technique. The data, analyzed in the light of the Transaction Costs theory allowed us to conclude that the transaction costs affect the selling agent for the additional production costs, which also affect the purchase price of the equipment and the buying agent, for the rise in the installation costs of the investment made or fixed assets acquired. Since the operations analyzed do not fit the rules contained in NBC TG 08 , transaction costs are elements that affect the determination of the sale price and are evidenced by accounting methods and legislation.

Keywords: Transaction cost. Trading costs. Contracts.

\section{Efectos Contables de los Costos de Transacción em las Operaciones de Pedido para Gran Tamaño}

\section{RESUMEN}

Los costos de transacción, también llamados costos comerciales, representan costos económicos que influyen en el proceso de toma de decisiones. A su vez, el proceso de toma de decisiones está influenciado por la información contable. Este estudio analizó una gran empresa de fabricación de maquinaria y equipo, con el objetivo de identificar cuáles son los costos de transacción presentes en las operaciones de comercialización de maquinaria y equipo para la industria de la harina de yuca, qué elementos 
Efeitos Contábeis dos Custos de Transação em Operações por encomenda de Equipamentos de Grande Porte Isielli Mayara Barzotto Martins Tierling, Juliane Andressa Pavão, Ivete Julieta Barzotto, Amanda Maria da

determinan la existencia de estos costos y cómo afectar los resultados contables. Se utilizaron técnicas de investigación cualitativa, con recopilación de datos documentales a través del modelo de contrato estándar, además de entrevistas. Los datos se analizaron a la luz de la Teoría de los Costos de Transacción, cuyos resultados se presentaron de manera descriptiva. El análisis permitió concluir que los costos de transacción afectan al agente de ventas a través de posibles costos de producción adicionales, y también afectan al agente de compra, con el fin de aumentar el precio de compra del equipo, aumentar los costos de instalación y causar pérdidas en el inversión realizada o activos fijos adquiridos. Dado que las operaciones analizadas no se ajustan a las reglas contenidas en NBC TG 08, los costos de transacción son elementos que afectan la determinación del precio de venta y se evidencian a través de los principios contables y la legislación.

Palabras clave: Costo de transacción. Costos comerciales. Contratos.

\section{INTRODUÇÃO}

A Teoria dos Custos de Transação (TCT) foi desenvolvida por Ronald Coase em 1937 e apresentou contribuições para as análises de custos, uma vez que propõe a existência dos custos de negociação, além dos custos de produção. Tal teoria demonstra que o processo de tomada de decisão é interferido pela simples existência de custos de transação de modo a exigir desde novos modelos de tomada de decisões até uma nova estrutura organizacional. O cerne da TCT é tornar os custos de transação conhecidos, a fim de mitigá-los ou eliminá-los (Coase, 1993).

Sob a ótica contábil, a análise de custos tem foco nos custos de produção e utiliza-se das abordagens tradicionais sobre as margens de comercialização, determinação dos Mark-ups e identificação dos pontos de equilíbrio financeiro e econômico. Já as análises econômicas sob a ótica da TCT buscam evidenciar as diferenças inevitáveis que as empresas possuem entre os custos de produção e os custos de transação, uma vez que apresentam ao mercado preços diversos e, consequentemente, condições competitivas também diferenciadas.

Esse confronto de valores (financeiros e não financeiros) existentes entre os custos de produção e os custos de transação é o motivo da diversificação de preços 
Efeitos Contábeis dos Custos de Transação em Operações por encomenda de Equipamentos de Grande Porte Isielli Mayara Barzotto Martins Tierling, Juliane Andressa Pavão, Ivete Julieta Barzotto, Amanda Maria da

existentes entre os preços pretendidos e necessários para a cobertura dos custos e os preços praticados no mercado. Assim, em função desse confronto de valores e da existência de coordenação dos mercados, arranjos de governança e forças estruturais do mercado, Arbage (2002) menciona que não há sentido em utilizar apenas a abordagem tradicional dos custos de produção.

Mesmo assim, o atual constructo das ciências contábeis a respeito da abordagem de custos restringe-se a determinação dos custos de produção por intermédio de eficazes sistemas de cálculos e verificações, não incluindo análises avançadas sobre a inclusão de custos de transação. Apesar disso, os custos de transação são reconhecidos pela contabilidade e citados em normativas específicas sobre sua forma de evidenciação.

É a partir desse contexto e das análises iniciais de Barzotto, Silva e Barzotto (2014) que este estudo empírico busca analisar os custos de transação em paralelo aos custos de produção, a fim de compreender a forma como se consubstanciam contabilmente quando sua ocorrência se dá a partir de contrato de compra e venda de fabricação encomendada pelo comprador diretamente ao fabricante.

Foi escolhido como objeto de estudo uma empresa que atua no segmento de fabricação de máquinas e equipamentos para indústrias de farinha de mandioca e derivados, situada no município de Araruna/PR. Esta empresa fabrica máquinas e equipamentos apenas por encomenda, por intermédio de contratos de compra e venda para entrega futura, não havendo negociações no mercado financeiro.

Buscou-se responder o seguinte problema de pesquisa: Quais custos de transação estão presentes nas operações de venda antecipada de máquinas e equipamentos para indústria de farinha de mandioca, quais elementos determinam a existência desses custos e como eles afetam os resultados contábeis?

Assim como propõe a TCT, este estudo contribuiu para a identificação dos custos de transação presentes nas negociações geradoras de receita para a empresa objeto de estudo, o que permite identificar alternativas de redução ou eliminação destes custos, além de auxílio no processo de tomada de decisão e na formação do preço de 
Efeitos Contábeis dos Custos de Transação em Operações por encomenda de Equipamentos de Grande Porte Isielli Mayara Barzotto Martins Tierling, Juliane Andressa Pavão, Ivete Julieta Barzotto, Amanda Maria da

venda das máquinas comercializadas. Este estudo proporciona ainda uma visão econômica sobre o processo de tomada de decisão, o qual tem fundamental importância na análise de resultados.

\section{REFERENCIAL TEÓRICO}

\subsection{Teoria dos Custos de Transação}

A Teoria dos Custos de Transação faz parte da Teoria da Nova Economia Institucional e foi desenvolvida por Ronald Coase em 1937 no livro "The nature of the firm". Ficou popularmente conhecida após Oliver Williamson, em meados de 1970, utilizá-la como base teórica para seus estudos.

Os custos de transação são concebidos como custos decorrentes de transações feitas pelos agentes quando estes transacionam com o mercado em diferentes etapas do processo de produção, podendo ser definidos como custos de negociação, de redação ou de cumprimento de contratos (Williamson, 1985). Fiane (2002) define que custos de transação não podem ser negligenciados pois são significativos a ponto de influenciar as decisões dos agentes econômicos na determinação da melhor forma de alocação dos recursos.

Para as atividades que dão funcionamento ao sistema econômico, Williamson (1985) identificou cinco fatores determinantes que demonstram a existência dos custos de transação:

a) Racionalidade Limitada: característica que demonstra que os agentes agem racionalmente, mas eventualmente de forma limitada quando processam as informações;

b) Complexidade: representa a limitação física do indivíduo em processar e utilizar as informações de forma precisa;

c) Incerteza: característica cujo efeito amplia lacunas e traz como consequência situações não previsíveis, sobre as quais o agente passa a ter dificuldade de prevenir riscos e problemas. A incerteza instiga a existência de atitudes 
Efeitos Contábeis dos Custos de Transação em Operações por encomenda de Equipamentos de Grande Porte Isielli Mayara Barzotto Martins Tierling, Juliane Andressa Pavão, Ivete Julieta Barzotto, Amanda Maria da

oportunistas e contribui para o aumento da necessidade de uma relação contratual, e não apenas verbal. Zylbersztajn (2000, p. 29) menciona ainda que a incerteza "pode levar ao rompimento contratual não oportunístico e está associada ao surgimento de custos transacionais irremediáveis" quando motivada pela racionalidade limitada;

d) Especificidade dos ativos: quanto maior o grau de especificidade, maiores serão os riscos e problemas, isto é, os custos de transação estarão mais vulneráveis se houver especificidade dos ativos. Ativos específicos são bens cuja finalidade é específica para negociação, não tendo o mesmo valor ou utilidade em outras negociações, seja pela não concretização da transação ou pelo rompimento do contrato (Williamson, 1985);

e) Oportunismo: característica do agente que age por interesse próprio, de modo egoísta e explícito. Williamson (1985, p. 47) explica que o oportunismo "se refere à revelação incompleta ou distorcida de informações, e especialmente aos esforços calculados de enganar, distorcer, desorientar, ofuscar ou de algum modo confundir". Williamson (1985, p. 47) menciona que "claramente, não fosse pelo oportunismo, os comportamentos poderiam ser governados apenas por regras".

A partir destes fatores que determinam a existência de custos de transação, a interação entre a racionalidade limitada, complexidade e incerteza geram assimetria de informações, que são "diferenças nas informações que as partes envolvidas em uma transação possuem, particularmente quando essa diferença afeta o resultado final da transação" (Fiani, 2002) e podem complicar os problemas de organização econômica (Williamson, 1985). 
Efeitos Contábeis dos Custos de Transação em Operações por encomenda de Equipamentos de Grande Porte Isielli Mayara Barzotto Martins Tierling, Juliane Andressa Pavão, Ivete Julieta Barzotto, Amanda Maria da

\subsection{A Natureza Jurídica dos Contratos e o Tratamento Contábil dos Custos de Transação}

Os contratos são instrumentos jurídicos que representam o acordo efetuado entre duas ou mais partes e estabelecem um regulamento de ações às partes interessadas (Gonçalves, 2004). A Teoria Geral dos Contratos define que há alguns princípios básicos que regem os contratos: a liberdade das partes ou autonomia da vontade, a força obrigatória do cumprimento, a relatividade dos efeitos contratuais (limitação contratual entre as partes), a boa fé objetiva, o equilíbrio econômico entre as partes, e a função social do contrato que reflete a relação entre o consensualismo e a autonomia da vontade (Uliana, 2017).

Os trabalhos de Hart e Holmström, premiados pelo Prêmio Nobel de Ciências Econômicas de 2016 por suas contribuições à teoria dos contratos, demonstram que as economias modernas são ligadas por inúmeros contratos. Dentre suas conclusões científicas está a afirmação de que "o desenvolvimento das formas contratuais é parte fundamental do desenvolvimento político, econômico e social das sociedades civilizadas" (Projuris, 2019).

Uma vez que podem efetivar-se a partir de diferentes transações, há diferentes tipos de contratos. Em relação à análise da existência de custos de transação, Fiani (2002) menciona a necessidade de analisar se cada contrato se ajusta à configuração da operação e apresenta quatro modelos básicos de contrato:

- Contratos que especificam no presente um determinado desempenho no futuro;

- Contratos que especificam no presente um determinado desempenho no futuro, condicionada a ocorrência de eventos definidos antecipadamente, isto é, contratos de cláusulas condicionais;

- Contratos de pouca duração, realizados apenas nos momentos em que as condições necessárias para a realização da transação efetivamente se concretizam, isto é, contratos de curtos prazos sequenciais; 
Efeitos Contábeis dos Custos de Transação em Operações por encomenda de Equipamentos de Grande Porte Isielli Mayara Barzotto Martins Tierling, Juliane Andressa Pavão, Ivete Julieta Barzotto, Amanda Maria da

- Contratos estabelecidos no presente, com o direito de selecionar no futuro um desempenho específico dentro do conjunto de desempenhos estipulado previamente, isto é, mediante o estabelecimento de uma relação de autoridade.

Em transações comerciais, o processo de tomada de decisão na compra/venda abrange a redação do contrato, sendo que o preço da operação é elemento essencial na negociação. Em se tratando de contratos de compra e venda para entrega futura, a qualificação dos agentes de compra é um dos principais fatores para a formação de preço de venda e isso deve-se ao fato de que a hipótese de existência de custos de transação é assertiva. Neste caso, é fundamental a análise de contratos para verificação da existência de elementos que geram custos de transação, porém a especificidade de ativos é certamente presente, dada a natureza do contrato (Oliveira, 1998 apud Trapp, 2010).

Sob a perspectiva contábil, o tratamento dado aos custos de transação são regulamentados pelo Pronunciamento Técnico - CPC 08 / Norma Brasileira de Contabilidade - NBC TG 08. Tal norma menciona que os custos de transação poderão ser reconhecidos, mensurados e divulgados somente quando forem resultantes de operações negociadas através do mercado financeiro.

Incorridos na distribuição primária de ações ou bônus de subscrição, na aquisição e alienação de ações próprias, na captação de recursos por meio da contratação de empréstimos ou financiamentos ou pela emissão de títulos de dívida, bem como dos prêmios na emissão de debêntures e outros instrumentos de dívida ou de patrimônio líquido (frequentemente referidos como títulos e valores mobiliários - TVM) (NBC TG 08, 2010).

Contabilmente, os custos de transação são considerados gastos incrementais e podem incluir gastos com elaboração de documentos, remuneração de serviços profissionais de terceiros, gastos com publicidade, taxas e comissões; custos de 
Efeitos Contábeis dos Custos de Transação em Operações por encomenda de Equipamentos de Grande Porte Isielli Mayara Barzotto Martins Tierling, Juliane Andressa Pavão, Ivete Julieta Barzotto, Amanda Maria da

transferência; custos de registro etc. Os custos de transação não incluem ágios ou deságios na emissão dos títulos e valores mobiliários, despesas financeiras, custos internos administrativos ou custos de carregamento (NBC TG 08, 2010).

É importante observar que, sob a perspectiva econômica, os custos de transação estão vinculados às formas de organização e coordenação da atividade econômica, podendo influenciar diferentes meios de alocação dos recursos produtivos. Por isso, é dado que o sistema de preços é o fator de coordenação dos recursos produtivos no mercado, e na firma esta função é desempenhada por relação de autoridade. Com isso, quanto maior for a internalização de transações sob a organização da firma, maiores serão os custos (Pondé, 1994).

Assim, relacionando a perspectiva contábil com a perspectiva econômica, concebe-se que o reconhecimento contábil dos custos de transação é limitado, uma vez que restringe-se aos custos percebidos quando movimenta-se títulos e ações nas bolsas de valores. Consequentemente, os demais custos de transação, percebidos também nas diversas operações, tanto de empresas de pequeno, médio ou grande porte, serão reconhecidos contabilmente como custos, gastos ou despesas conforme a sua natureza específica, como por exemplo, honorários advocatícios quando há contratação para confecção de contratos, despesas financeiras diversas, dentre outras (Pondé, 1994; NBC TG 08).

\subsection{Pesquisas Relacionadas}

A TCT tem sido um mecanismo de análise dos estudos organizacionais, nas abordagens sob escopo da Teoria Institucional, principalmente em estudos da área econômica e do campo da administração. Os principais fatores analisados são os que influenciam a existência dos custos de transação, os aspectos comportamentais dos agentes econômicos, características do ambiente institucional e a estrutura de governança das organizações (Arbage, 2002; Peixe, Rosa Filho, de Abreu Passos, Formiga, \& Peixe, 2016).

Peixe et al. (2016) mencionam que os estudos atuais sobre a TCT abrangem o 
Efeitos Contábeis dos Custos de Transação em Operações por encomenda de Equipamentos de Grande Porte Isielli Mayara Barzotto Martins Tierling, Juliane Andressa Pavão, Ivete Julieta Barzotto, Amanda Maria da

setor público e privado, havendo focos de pesquisa bastante diferenciados entre os setores. Os estudos no setor privado buscam analisar, principalmente, a hierarquia da estrutura organizacional das empresas e a interação que o mercado e os agentes econômicos possuem (Peixe et al., 2016).

Dos estudos mais recentes, destaca-se os trabalhos de Gusmão e Garcias (2008) sobre a eficiência econômica da instituição no mercado, Santos e Calixto (2010) sobre o impacto das normas e decretos na gestão das organizações, Gonzaga et al. (2015) sobre elementos que disciplinam a gestão de custos interorganizacionais, e ainda, Oliveira, Sales, de Oliveira, Bezerra e de Souza Neto (2019) sobre a relação da existência de custos de transação com o planejamento tributário das empresas.

Em relação aos estudos no setor público, observa-se que focam nos custos de transação existentes na elaboração de políticas públicas, na sua implementação, manutenção, fiscalização e avaliação, a partir das interações entre os atores do serviço público (Peres, 2007; Peixe et al., 2016). Dos estudos mais recentes nesta área, destaca-se os trabalhos de Nuitin, Curi e Gallon (2010), que analisa os custos de transação presentes nos controles internos das instituições públicas, e Santos et al. (2010), que analisa o impacto dos custos de transação na prestação dos serviços do setor público.

A sessão seguinte apresenta os métodos e técnicas utilizados no desenvolvimento deste estudo.

\section{METODOLOGIA}

Concebe-se que este estudo possui natureza qualitativa e descritiva. Richardson (1999) descreve que "os estudos que empregam uma metodologia qualitativa podem descrever a complexidade de determinado problema, analisar a interação de certas variáveis, compreender e classificar processos dinâmicos". Sobre a pesquisa descritiva, Vergara (2019), menciona que tem o intuito de "expor características de determinada população ou fenômeno, sem o compromisso de explicar os fenômenos que descreve, 
Efeitos Contábeis dos Custos de Transação em Operações por encomenda de Equipamentos de Grande Porte Isielli Mayara Barzotto Martins Tierling, Juliane Andressa Pavão, Ivete Julieta Barzotto, Amanda Maria da

embora sirva de base para tal explicação". Uma vez que a preocupação central desta pesquisa é analisar os custos de transação presentes especificamente em operações de venda antecipada, descrevendo os elementos que determinam sua existência e as possíveis implicações no resultado do exercício são advindas destes custos, justifica-se a utilização dos métodos qualitativo e descritivo.

Utilizou-se como objeto de pesquisa uma empresa situada no município de Araruna-PR, cuja atividade econômica fim é a fabricação de máquinas e equipamentos para indústria de farinha de mandioca e derivados. Esta empresa desenvolve atividade fabril apenas por encomenda, cuja transação de compra e venda é efetuada após negociação do produto a ser fabricado por meio de um contrato formal.

Para coleta dos dados, utilizou-se a pesquisa documental e entrevista semiestruturada. A empresa objeto de estudo possui um contrato formal com texto padrão, utilizado como base de negociação nas operações de comercialização. Tal contrato foi lido e analisado à luz da TCT, de modo a identificar, comparar e descrever os custos de transação nele presentes.

Durante o processo de leitura do contrato, foram realizadas interpretações das cláusulas contratuais, além de análises da concordância da prática comercial em relação aos detalhes descritos no contrato. A partir disso, foram realizadas anotações de todas as informações extraídas do contrato em relação aos custos de transação, bem como, as interpretações e consequências identificadas.

A técnica de entrevista semiestruturada foi utilizada para complementação das informações anteriormente extraídas do contrato. Foram dirigidas perguntas abertas, com o intuito de esclarecer as informações do contrato, além de informações sobre a prática e a realidade organizacional. A entrevista foi realizada com o proprietário da empresa objeto deste estudo.

A sessão seguinte apresenta os resultados da pesquisa descritiva. 
Efeitos Contábeis dos Custos de Transação em Operações por encomenda de Equipamentos de Grande Porte Isielli Mayara Barzotto Martins Tierling, Juliane Andressa Pavão, Ivete Julieta Barzotto, Amanda Maria da

\section{ANÁLISE DOS RESULTADOS}

Esta sessão apresenta a análise efetuada sobre o contrato de compra e venda de equipamentos e instalações para indústria de farinha de mandioca e derivados, de uma organização cujo nome empresarial foi mantido em sigilo, situada no município de Araruna - PR. A empresa é optante pelo regime tributário Simples Nacional. O contrato analisado é um modelo padrão utilizado pela empresa para vendas sem qualquer tipo de financiamento, pelo qual são estipuladas a forma de pagamento e todas as demais condições da operação transacionada.

O primeiro passo deste estudo foi analisar, à luz da TCT, quais elementos geradores de custos de transação estão presentes no contrato de comercialização antecipada com entrega futura. Foram identificadas várias situações que geram custos de transação, bem como os possíveis efeitos e consequências. Juntamente com os elementos identificados, apresenta-se quais custos de transação são gerados, que é o segundo objetivo específico deste estudo.

A primeira cláusula apresenta um detalhamento das características do produto comercializado, o qual é objeto do contrato. Verificou-se que há forte presença de Especificidade de Ativos, uma vez que o produto comercializado sempre apresenta medidas específicas. Caso o vendedor não fabrique um produto com as medidas e especificações definidas no contrato, o produto não servirá para o cliente e dificilmente será passível de comercialização para outro cliente.

Ao indagar o proprietário da empresa a respeito das implicações sobre a fabricação de equipamento com finalidade específica ao cliente, ressaltou-se a necessidade de "cuidados na elaboração do preço de venda". Com isso, foi identificado que a margem de lucro atribuída ao equipamento na elaboração do seu preço de venda é superior à margem de lucro de equipamentos comuns, ou seja, que facilmente seriam vendidos a outro cliente. Apesar disso, a margem de lucro não pode ser tão superior a ponto de inviabilizar a negociação de venda. 
Efeitos Contábeis dos Custos de Transação em Operações por encomenda de Equipamentos de Grande Porte Isielli Mayara Barzotto Martins Tierling, Juliane Andressa Pavão, Ivete Julieta Barzotto, Amanda Maria da

Identificou-se que, nestes casos, a margem de lucro aplicada na formação do preço de venda é afetada positivamente pela quantidade de tempo e esforços gastos na negociação e fechamento do contrato, e pelo tamanho e quantidade de equipamentos a serem fabricados ao cliente. Da mesma forma, a margem de lucro é afetada negativamente pela demanda de produção existente (já negociada e em fila de fabricação) na empresa e pela possibilidade de perda da negociação à concorrência. Cabe ressaltar que a única empresa concorrente é alemã, o que exigiria negociação por meio de importação.

Ainda na primeira cláusula há informações adicionais ao produto fabricado, mais especificamente sobre sua instalação no local de destino. Neste item, o vendedor sugere que o comprador contrate serviço de terceiros para a instalação do equipamento, e dá a opção de o próprio vendedor realizar a montagem e desmontagem do equipamento, mediante pagamento a parte.

Sobre isso, destaca-se a existência de incerteza e possível assimetria de informações. O elemento incerteza foi identificado pois o cliente tem a opção de contratar o serviço de terceiros para instalação do equipamento, mas dificilmente terá certeza de haver serviço terceirizado com conhecimento e técnica suficiente para a prestação deste serviço específico. Em relação a assimetria de informações, deve-se ao fato de haver conhecimentos diferentes entre comprador e vendedor sobre a instalação do produto comprado/vendido e essa diferença pode afetar o resultado financeiro da operação, principalmente para o comprador que possivelmente não detém todas as informações necessárias para a decisão entre contratar a própria empresa para instalação do equipamento ou terceirizar. Neste caso, a presença de incerteza e assimetria de informações gera custos de transação, o qual é refletido em possíveis custos adicionais na instalação do produto comprado.

Os itens III e IV da primeira cláusula mencionam ainda a responsabilidade que 0 comprador possui sobre a instalação elétrica e isolamento térmico do equipamento comprado. Sobre isso, identificou-se também a presença de assimetria de informações, incerteza e racionalidade limitada, pois as especificações técnicas 
Efeitos Contábeis dos Custos de Transação em Operações por encomenda de Equipamentos de Grande Porte Isielli Mayara Barzotto Martins Tierling, Juliane Andressa Pavão, Ivete Julieta Barzotto, Amanda Maria da

deveriam conter informações suficientes para que o equipamento seja corretamente instalado e não acarrete prejuízos na operação. Apesar de haver indicações e especificações técnicas para instalação do equipamento, e o contrato especificar a necessidade de contratação de empresa especializada para realização do isolamento térmico do equipamento, quanto maior for a especificidade do ativo, maior será a incerteza e a possibilidade de haver assimetria de informações e racionalidade limitada. Neste caso, a presença de incerteza, assimetria de informações e racionalidade limitada gera custos de transação, possivelmente transformados em custos adicionais na instalação do produto comprado.

A cláusula $2^{\circ}$ menciona informações sobre a conservação e uso do bem adquirido. Identificou-se a presença de incerteza e assimetria de informações nesta cláusula. A incerteza está presente pois o contrato especifica a responsabilidade da compradora sobre a limpeza, uso, manuseio e conservação do equipamento comprado. O vendedor oferece instruções de uso, porém há situações não especificadas que podem acarretar em estragos. A assimetria de informações está presente, pois se 0 comprador e o vendedor não tiverem pleno conhecimento sobre as condições durante montagem e manuseio da máquina, é possível que situações não especificadas no contrato surjam e gere mais custos de transação que resultam em custos de produção adicionais.

Ao encerrar as negociações e firmarem contrato, fica estipulado entre as partes o valor total estabelecido e as formas de pagamentos. Tais condições foram especificadas nas cláusulas $4^{\circ}$ e $5^{\circ}$ do contrato. $O$ contrato descreve que, se houver inadimplência e a empresa compradora não se pronunciar para possível esclarecimento ou um novo acordo, a cláusula $12^{\circ}$ que menciona que a parte que infringir alguma cláusula do contrato incorrerá uma multa de $20 \%$ do valor do contrato, serve como amparo à empresa vendedora.

O contrato prevê que a inadimplência de qualquer parcela poderá ocasionar o interrompimento da fabricação dos produtos, gerando custos operacionais para as duas empresas: à compradora em relação aos investimentos já pagos pelo produto 
Efeitos Contábeis dos Custos de Transação em Operações por encomenda de Equipamentos de Grande Porte Isielli Mayara Barzotto Martins Tierling, Juliane Andressa Pavão, Ivete Julieta Barzotto, Amanda Maria da

encomendado, e à vendedora pelos recursos já empregados no produto encomendado. Com isso, verifica-se a existência de incerteza em relação ao recebimento (vendedor) e, por outro lado, a existência de oportunismo em relação ao pagamento (comprador). Nestes casos, o oportunismo gera custos de transação, que por sua vez resulta em custos operacionais não previstos pelo vendedor.

Em relação à garantia da transação, os direitos previstos por cada parte requerem observação da parte contrária, uma vez que pode ser gerador de custos. Consta especificado na Cláusula $9^{\circ}$ que não haverá garantia caso haja dano no equipamento e este estiver desmontado, modificado ou reparado, ou caso a avaria do equipamento tenha sido causada por manuseio errôneo, descumprimento das instruções dadas pela vendedora, por sobrecarga, ou seja, por dano comprovadamente voluntário, ou ainda falta de manutenção preventiva. Embora especificada as situações onde não há garantia, tal previsão permite o surgimento de oportunismos, pois várias situações podem ser "geradas" a fim de aproveitar-se da garantia (no caso do comprador) ou da não garantia (no caso do vendedor). Por outro lado, a assimetria de informações por parte da empresa compradora pode contribuir para a não aplicação da garantia prevista no contrato, uma vez que a falta de informações é fator de riscos neste caso. Com isso, verificou-se que, em relação à garantia dos produtos, a existência de oportunismo e assimetria de informações indica o possível surgimento de custos de transação, que podem gerar perda do investimento realizado pela empresa compradora.

Por fim, a Cláusulas $11^{\circ}$ prevê que a transação negociada via contrato possui caráter irrevogável, com declaração de desistência do direito de arrependimento (conforme previsto no Artigo 1095 do Código Civil), estando os herdeiros ou sucessores, inclusive, responsáveis pelo cumprimento do contrato. E a Cláusula $12^{\circ}$ prevê a imposição de multa pecuniária equivalente a $20 \%$ do valor contratual caso alguma cláusula seja infringida, além da indenização por perdas e danos, caso haja. Ambas as cláusulas asseguram a não existência de custos de transação para a vendedora, em relação a perdas absolutas sobre o equipamento vendido. 
Efeitos Contábeis dos Custos de Transação em Operações por encomenda de Equipamentos de Grande Porte Isielli Mayara Barzotto Martins Tierling, Juliane Andressa Pavão, Ivete Julieta Barzotto, Amanda Maria da

Em suma, percebe-se que os elementos geradores de custos de transação sempre apontam para o agente comprador, ou seja, em sua maioria, os custos de transação são gerados para o comprador, mesmo a transação sendo realizada através de contrato formal, com garantias legais. Existem ainda custos de transação gerados apenas para a empresa vendedora e outros gerados para ambas as partes, porém em menor quantidade. É possível que a geração de custos de transação em maior quantidade ao agente comprador seja proporcional ao tamanho do risco do negócio, uma vez que trata-se de compra de equipamento de grande porte, cujo ativo é classificado como específico.

Verificou-se também que os custos de transação refletem ao comprador elevação do preço de aquisição do equipamento, possível aumento dos custos de instalação e possíveis perdas do investimento/imobilizado adquirido. Para o vendedor, os custos de transação refletem possíveis custos de produção adicionais. Assim, a incidência de custos de transação prejudica tanto 0 agente vendedor mas, principalmente, o agente comprador. A Figura 1 demonstra os tipos de custos que envolvem a negociação analisada. 
Efeitos Contábeis dos Custos de Transação em Operações por encomenda de Equipamentos de Grande Porte

Isielli Mayara Barzotto Martins Tierling, Juliane Andressa Pavão, Ivete Julieta Barzotto, Amanda Maria da

Silva

\begin{tabular}{|c|c|c|c|c|}
\hline & Situação & $\begin{array}{l}\text { Elementos geradores } \\
\text { de custos de } \\
\text { transação }\end{array}$ & Consequência & $\begin{array}{l}\text { Agente } \\
\text { afetado }\end{array}$ \\
\hline 1 & $\begin{array}{l}\text { Produto comercializado sob } \\
\text { medida }\end{array}$ & Especificidade do ativo & $\begin{array}{l}\text { Afeta a determinação da } \\
\text { margem de lucro (quanto mais } \\
\text { específico for o ativo, maior } \\
\text { será a margem de lucro } \\
\text { aplicada), elevando o preço do } \\
\text { equipamento fabricado. }\end{array}$ & Comprador \\
\hline 2 & $\begin{array}{lr}\text { Instalação local } & \text { do } \\
\text { equipamento } & \text { sob } \\
\text { responsabilidade } & \text { do } \\
\text { comprador } & \\
\end{array}$ & $\begin{array}{c}\text { Incerteza } \\
\text { Assimetria de } \\
\text { informações }\end{array}$ & $\begin{array}{l}\text { Custos adicionais não } \\
\text { previstos na instalação }\end{array}$ & Comprador \\
\hline 3 & $\begin{array}{lrr}\text { Instalação } & \text { elétrica } & \text { e } \\
\text { isolamento } & \text { térmico } & \text { do } \\
\text { equipamento } & \text { sob } \\
\text { responsabilidade } & \text { do } \\
\text { lomprador } & \\
\end{array}$ & $\begin{array}{c}\text { Incerteza } \\
\text { Assimetria de } \\
\text { informações } \\
\text { Racionalidade limitada }\end{array}$ & $\begin{array}{l}\text { Custos adicionais não } \\
\text { previstos na instalação }\end{array}$ & Comprador \\
\hline 4 & \begin{tabular}{lr|} 
Limpeza, uso, manuseio e \\
conservação & do \\
equipamento & sob \\
responsabilidade & do \\
comprador & \\
\end{tabular} & $\begin{array}{c}\text { Incerteza } \\
\text { Assimetria de } \\
\text { informações }\end{array}$ & $\begin{array}{l}\text { Custos de produção adicionais } \\
\text { não previstos }\end{array}$ & Vendedor \\
\hline 5 & 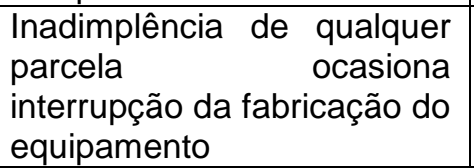 & $\begin{array}{l}\text { Oportunismo } \\
\text { Incerteza }\end{array}$ & $\begin{array}{l}\text { Custos de produção adicionais } \\
\text { não previstos }\end{array}$ & Vendedor \\
\hline 6 & $\begin{array}{l}\text { Dano comprovadamente } \\
\text { voluntário ao equipamento } \\
\text { ou falta de manutenção } \\
\text { preventiva }\end{array}$ & $\begin{array}{l}\text { Oportunismo } \\
\text { Assimetria de } \\
\text { informações }\end{array}$ & $\begin{array}{l}\text { Perdas no investimento ou do } \\
\text { valor ativo imobilizado } \\
\text { adquirido }\end{array}$ & Comprador \\
\hline
\end{tabular}

Figura 1. Tipos de custos identificados.

Fonte: Dados da pesquisa.

Em seguida, analisou-se qual o tratamento contábil deve ser dado aos custos de transação presentes nas negociações objeto deste estudo. Dadas as situações geradoras de custos de transação identificadas, conforme demonstra o Quadro 1 e mediante o fato de que as transações analisadas não foram objeto de comercialização por meio do mercado financeiro, conclui-se que é extinta a necessidade de observação ao regramento contido na NBC TG 08 (2010).

Em relação à margem de lucro afetada, é necessário que tal consequência seja considerada na aplicação do Mark-up para formação do preço de venda. Uma vez que 
Efeitos Contábeis dos Custos de Transação em Operações por encomenda de Equipamentos de Grande Porte Isielli Mayara Barzotto Martins Tierling, Juliane Andressa Pavão, Ivete Julieta Barzotto, Amanda Maria da

os custos de transação afetam a margem de lucro positivamente, ou seja, implicam em aumento da margem aplicada, conclui-se que os custos de transação contribuem para o aumento da receita operacional do agente vendedor.

Em relação aos custos de produção afetados, é necessário contabilizá-los de acordo com os princípios e legislação contábeis vigentes. Uma vez que sua evidenciação se dá por intermédio do Resultado do Exercício, conclui-se que os custos de transação implicam em redução do lucro operacional.

A sexta situação identificada, conforme demonstra o Quadro 1, aponta para a possibilidade de incidência de aumento dos custos de investimento ou perdas do ativo imobilizado, conforme especificidade do comprador. Em se tratando de aumento dos custos de investimento, conclui-se que os custos de transação podem contribuir para o aumento do ativo. Em se tratando de perdas do ativo imobilizado, conclui-se que os custos de transação podem implicar em redução do ativo.

Finalizada as análises desta investigação empírica, a sessão seguinte apresenta as considerações finais do estudo.

\section{CONSIDERAÇÕES FINAIS}

Este estudo foi direcionado a identificar quais são os custos de transação presentes na venda antecipada de equipamentos para indústria de farinha de mandioca e derivados e como estes custos podem afetar os resultados contábeis.

Primeiramente, por meio de leitura e análise, à luz da TCT, do contrato do contrato de venda antecipada de máquinas e equipamentos para indústria de farinha de mandioca e derivados, buscou-se identificar quais elementos que geram custos de transação estão presentes nestas operações. Em seguida, buscou-se verificar quais custos de transação são gerados nestas operações e, por fim, buscou-se analisar qual tratamento contábil é dado a estes custos de transação identificados.

Conclui-se que os custos de transação afetam o agente vendedor, mas, principalmente, são gerados para o agente comprador. Para o agente vendedor, os 
Efeitos Contábeis dos Custos de Transação em Operações por encomenda de Equipamentos de Grande Porte Isielli Mayara Barzotto Martins Tierling, Juliane Andressa Pavão, Ivete Julieta Barzotto, Amanda Maria da

custos de transação refletem possíveis custos de produção adicionais, o que eleva os custos do equipamento fabricado. Para o agente comprador, os custos de transação elevam o preço de aquisição do equipamento, podem implicar em aumento dos custos de instalação e podem implicar em perdas de investimento ou de valor do ativo imobilizado adquirido.

Por fim, conclui-se que, neste caso, não há possibilidade de observação às regras contidas na NBC TG 08 (2010), devendo haver contabilização dos itens financeiros e não financeiros por meio das regras gerais da contabilidade gerencial e da contabilidade geral.

Cabe ressaltar que tais resultados não podem ser generalizados, uma vez que as situações analisadas são específicas da firma objeto de estudo. Dessa forma, em outras firmas, as mesmas situações podem afetar o patrimônio de diferentes formas, necessitando novas análises.

São sugestões para futuras pesquisas a análise das diferentes alternativas para a redução ou eliminação dos custos de transação existentes no contrato; e a análise da influência do nível de especificidade do ativo e sua composição para os diferentes agentes econômicos.

\section{REFERÊNCIAS}

Arbage, A. P. (2002). Economia dos Custos de Transação e a Formação de Estratégias Interorganizacionais: uma revisão teórica na busca de um framework. ENANPAD. Salvador, BA, Brasil, 27.

Barzotto, I. J., Silva, A.M., \& Barzotto, I. M. (2014). Custos de transação em operações de vendas futuras: um estudo aplicado à empresa Alfa Indústria e Comércio Ltda. Encontro de Produção Científica e Tecnológica - EPCT, Campo Mourão, PR, Brasil, 9.

Coase, R. H. (1993). The nature of the firm: origins, evolution, and development. Oxford University Press, USA, $256 \mathrm{p}$.

Fiani, R. (2002). Teoria dos custos de transação. In: Economia industrial. Elsevier Editora Ltda. 
Efeitos Contábeis dos Custos de Transação em Operações por encomenda de Equipamentos de

Grande Porte

Isielli Mayara Barzotto Martins Tierling, Juliane Andressa Pavão, Ivete Julieta Barzotto, Amanda Maria da

Silva

Gonçalves, C. R. (2004). Direito Civil Brasileiro. São Paulo: Saraiva.

Gonzaga, R. P., Aillón, H. S., de Almeida Fehr, L. C. F., Borinelli, M. L., \& Rocha, W. (2015). Mecanismos Disciplinadores da Gestão de Custos Interorganizacionais e Economia dos Custos de Transação: um ensaio teórico. Revista de Educação e Pesquisa em Contabilidade (REPeC), 9(3).

Gusmão, I. B., \& Garcias, P. M. (2008). Análise dos custos de transação, das oportunidades de arbitragem e da eficiência de mercado nas empresas brasileiras emissoras de ADR. In: Congresso USP de Controladoria e Contabilidade (Vol. 5, pp. 125-141). São Paulo-SP.

NBC TG 08 (2010). Normas brasileiras de contabilidade: Custos de Transação e Prêmios na Emissão de Títulos e Valores Mobiliários. Conselho Federal de Contabilidade. Recuperado de: https://www1.cfc.org.br/sisweb/sre/detalhes_sre.aspx?Codigo=2010/001313. Acesso em: 13/jul/2019.

Nuintin, A. A., Curi, M. A., \& Gallon, A. V. (2010). Contratos administrativos e seus controles internos sob a ótica da economia dos custos de transação: estudo em um campi de uma instituição federal de ensino superior mineira. In: Congresso Brasileiro de Custos, ABC, Belo Horizonte, MG, Brasil, 17.

Oliveira, O. C., Sales, L. B., de Oliveira, A. M., Bezerra, A. E. F., \& de Souza Neto, M. O. (2019). Custo de transação econômica e planejamento tributário. Revista Ambiente Contábil, 11(2), 175-198.

Peixe, A. M. M., da Rosa Filho, C., de Abreu Passos, G., Formiga, M. V., \& Peixe, B. C. S. (2016). Custos de Transação Aplicados no Setor Público e Privado: uma análise bibliométrica das edições do Congresso Brasileiro de Custos e USP International Conference in Accounting. In: Congresso Brasileiro de Custos, ABC, Porto de Galinhas, PE, Brasil, 23.

Peres, U. D. (2007). Custos de transação e estrutura de governança no setor público. Revista Brasileira de Gestão de Negócios-RBGN, 9(24), 15-30.

Pondé, J. L. (1994). Coordenação, custos de transação e inovações institucionais. Texto para discussão. Campinas, UNICAMP.

Projuris. A teoria dos contratos e o Nobel de Economia. Recuperado de: https://www.projuris.com.br/teoria-dos-contratos/. Acesso em: 13/jul/2019.

Richardson, R. J. (1999). Pesquisa social: métodos e técnicas. São Paulo: Atlas. 
Efeitos Contábeis dos Custos de Transação em Operações por encomenda de Equipamentos de Grande Porte

Isielli Mayara Barzotto Martins Tierling, Juliane Andressa Pavão, Ivete Julieta Barzotto, Amanda Maria da

Santos, E. S., \& Calixto, L. (2010). Impactos do início da harmonização contábil internacional (Lei 11.638/07) nos resultados das empresas abertas. RAE eletrônica, $9(1), 0-0$.

Santos, M. R., de Jesus Nagahama, H., \& de Oliveira, A. M. B. (2010). Considerações sobre os riscos do pregão eletrônico nas licitações de Instituições Federais de Ensino Superior: um estudo de caso sob a ótica da teoria de custos de transação. In: Congresso Brasileiro de Custos, ABC, Belo Horizonte, MG, Brasil, 17.

Trapp, G. P. (2010). A Fragilidade Institucional do Mercosul e os seus impactos sobre o Mercado de trabalho. (Tese de Doutorado), Universidade Federal do Rio Grande do Sul, UFRGS, Porto Alegre, RS, Brasil.

Uliana, M. L. (2017). Princípios contratuais: dos princípios tradicionais aos modernos. Recuperado de: https://mlu25.jusbrasil.com.br/artigos/450052172/direito-civilcontratos-principios-contratuais-dos-principios-tradicionais-aos-modernos. Acesso em: 19/jul/2019.

Vergara, S. C. (2019). Projetos e relatórios de pesquisa. São Paulo: Atlas.

Williamson, O. (1985). The Economic Institutions of Capitalism. New York: Free.

Zylbersztajn, D., \& Neves, M. F. (Org.) (2000). Economia e gestão de negócios agroalimentares. São Paulo: Pioneira.

Data de Submissão: 05/02/2020

Data de Aceite: 21/07/2020 